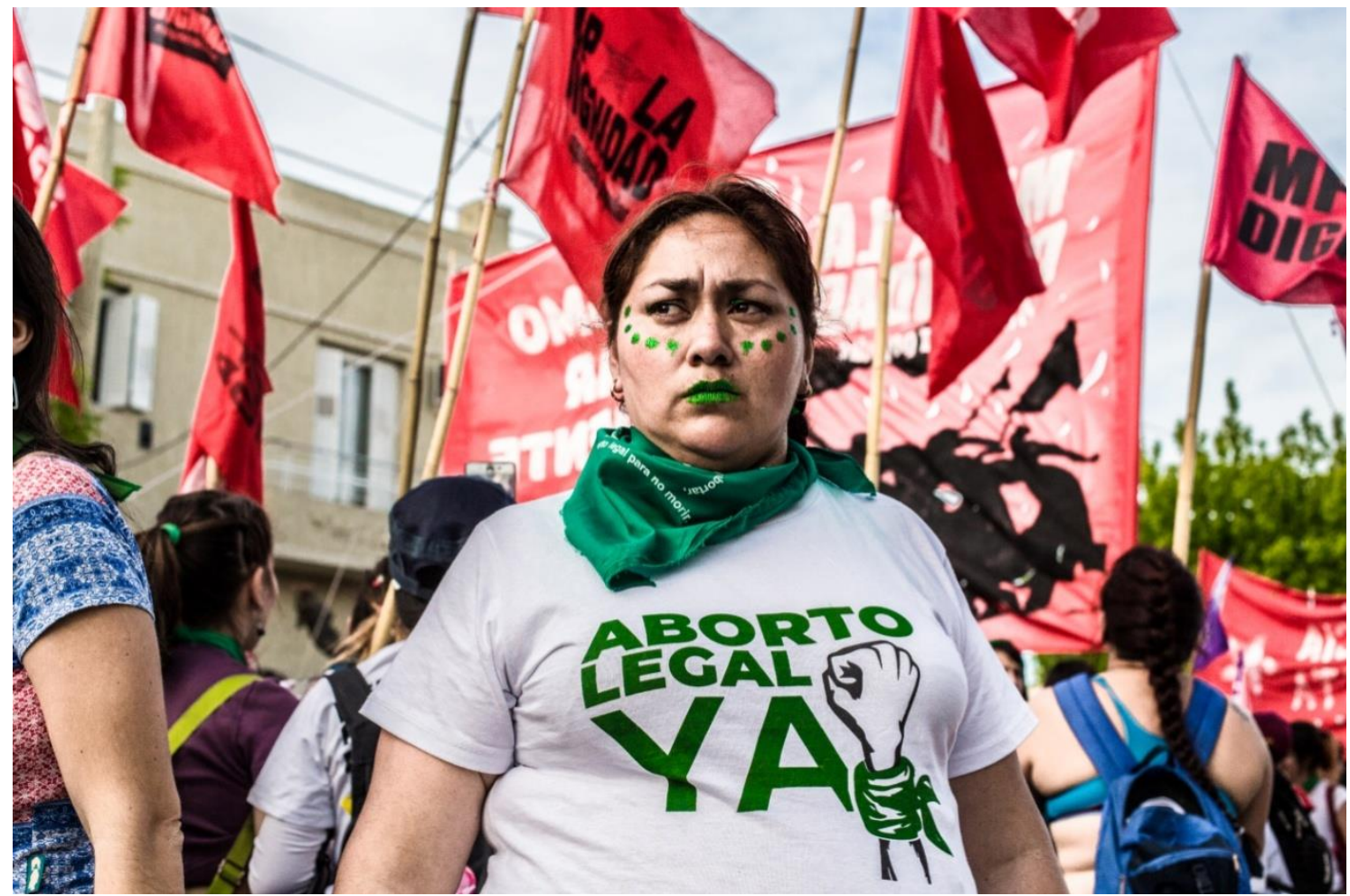

FOTOS: Irina Morán - Revista Alfilo - Periodista Feminista. Militante de Ni Una Menos Córdoba y Mujeres por un parto Respetado 


\title{
PROVOCAÇÕES FEMINISTAS NO SISTEMA SOCIOEDUCATIVO: PENSANDO EDUCAÇÃO PARA/COM HOMENS JOVENS HOMENS
}

\author{
Jimena de Garay Hernández ${ }^{1}$ \\ Anna Paula Uziel ${ }^{2}$
}

\begin{abstract}
Resumo: O presente trabalho apresenta algumas reflexões que surgiram em uma pesquisa-intervenção realizada em uma unidade masculina de internação do Sistema Socioeducativo do Rio de Janeiro. A partir de uma cartografia feminista e de diversas propostas, atividades e parcerias, foi possível provocar as noçães sobre socioeducação e educação, bem como a forma em que elas poderiam considerar gênero e sexualidade como eixos fundamentais de ação, tanto em estabelecimentos de privação de liberdade quanto na fundamentação de uma transformação social mais ampla. Para isso, foi fundamental um olhar crítico que, permanentemente, articulasse os dispositivos de gênero, raça, classe social, geração, sexualidade, escolaridade e localidade, como forças que compõem os processos de subjetivação e os mecanismos institucionais que os circunscrevem.
\end{abstract}

Palavras-chave: cartografia feminista; socioeducação; performatividades masculinas.

\section{PROVOCACIONES FEMINISTAS EN EL SISTEMA SOCIOEDUCATIVO: pensando educación para/con hombres jóvenes}

Resumen: El presente trabajo presenta algunas reflexiones que surgieron en una investigaciónintervención realizada en una unidad masculina de internación del Sistema Socioeducativo de Rio de Janeiro. A partir de una cartografía feminista y a través de diversas propuestas, actividades y colaboraciones, fue posible provocar las nociones sobre socioeducación y educación, así como la forma en que estas podrían considerar género y sexualidad como ejes fundamentales de acción tanto en establecimientos de privación de libertad, como en la fundamentación de una transformación social más amplia. Para eso, fue fundamental una mirada crítica que permanentemente articulara los dispositivos de género, raza, clase social, generación, sexualidad, escolaridad y localidad, como fuerzas que componen los procesos de subjetivación y los mecanismos institucionales que los circunscriben.

Palabras clave: cartografía feminista; socioeducación; performatividades masculinas.

\section{INTRODUÇÃO}

No Brasil, o Estatuto da Criança e do Adolescente faz uma separação entre estabelecimentos de atendimento a crianças e jovens que precisam estar sob medida de proteção, em programas de acolhimento, por terem sido violados/as em seus direitos e aqueles/as que cometeram ou foram acusados/as de cometer ato infracional. Como são

\footnotetext{
${ }^{1}$ Doutora em Psicologia Social (UERJ). Mestra em Psicologia Social - Universidade do Estado do Rio de Janeiro. Possui graduação em Psicologia - Universidad Nacional Autonoma de Mexico. Tem experiência na área de Psicologia social, atuando, principalmente, nos seguintes temas: sociedade, gênero, sexualidade, educação, infância, juventude, feminismo, homoparentalidade e privação de liberdade. Tem colaborado com diversas organizações do movimento feminista e LGBT.

${ }^{2}$ Graduação em Filosofia pela Universidade Federal do Rio de Janeiro (1988), graduação em Psicologia pela Universidade do Estado do Rio de Janeiro, mestrado em Psicologia (Psicologia Clínica) pela Pontifícia Universidade Católica do Rio de Janeiro e doutorado em Ciências Sociais pela Universidade Estadual de Campinas. É professora associada da Universidade do Estado do Rio de Janeiro, coordenadora do LIDIS - Laboratório Integrado em Diversidade Sexual e de Gênero, Políticas e Direitos e pesquisadora associada do Centro Latino-Americano em Sexualidade e Direitos Humanos (CLAM/IMS/UERJ). Já foi coordenadora do Programa de Pós-Graduação em Psicologia Social (PPGPS), em dois mandatos. Seus principais campos de interesse são Psicologia Jurídica e Sexualidade.
}

Momento: diálogos em educação, E-ISSN 2316-3100, v. 28, n. 3, p. 285-302, set./dez, 2018. 
menores de 18 anos, são "penalmente inimputáveis" (Brasil, 1990, artigo 104), por isso são alocados/as no Sistema Socioeducativo, cujas medidas podem ser cumpridas em meio aberto (advertência, reparação do dano, prestação de serviços à comunidade, liberdade assistida) ou em privação de liberdade (semiliberdade e internação em estabelecimento educacional). Nesse contexto, nas medidas socioeducativas

\begin{abstract}
busca-se práxis pedagógica a partir de objetivos e critérios metodológicos próprios de um trabalho social reflexivo, crítico e construtivo. Como desdobramento, há promoção pessoal e social através de um trabalho de orientação de educação formal, de atividades pedagógicas, de lazer, esportivas, culturais e de educação profissional, bem como demais questões inerentes ao desenvolvimento do sujeito frente aos desafios da vida em liberdade (ABDALLA, 2016b, p.348).
\end{abstract}

No entanto, as condições atuais do Sistema frente às práticas políticas de superencarceramento, criminalização da pobreza, genocídio da juventude negra, militarização das cidades e cooptação de jovens empobrecidos/as e periféricos/as, por parte das facções criminosas, são de superlotação e extrema precariedade, o que dificulta, enormemente, o cumprimento dos seus objetivos. Assim, apesar de a socioeducação se apresentar como um modelo que, mesmo docilizador, é mais cuidadoso que o modelo puramente prisional, ao propor um projeto pedagógico de inclusão social (ABDALLA, 2016b); ele é, frequentemente, comparado com o Sistema Prisional e chamado de cadeia3 pelos jovens, apontando suas semelhanças. Por exemplo, no Rio de Janeiro, apesar de o Departamento Geral de Ações Socioeducativas (Novo Degase), atualmente, fazer parte da Secretaria Estadual de Educação, existem projetos para que seja inserido na Secretaria de Segurança, como acontece em alguns estados.

Estes movimentos e os discursos que os contornam evidenciam a vontade de punição ao invés do investimento social em alternativas de vida e garantia dos direitos dos/as jovens. Nesse sentido, apesar de observar esforços de "humanização" do Sistema Socioeducativo, através de noções como "protagonismo juvenil" e "cultura da paz", bem como de tentativas de romper paradigmas violentos que, historicamente, marcaram a instituição-organização, este está saturado de práticas e condições muito semelhantes ao sistema dos adultos. Por exemplo, mesmo sendo obrigação do Degase garantir o direito à educação fundamental para todos/as os/as jovens que nele estão, atualmente

\footnotetext{
${ }^{3}$ Ao longo do texto, as palavras e expressões provindas do campo de pesquisa serão apresentadas em itálico.
}

Momento: diálogos em educação, E-ISSN 2316-3100, v. 28, n. 3, p. 285-302, set./dez, 2018. 
não há vaga para todos/as, o que constitui uma violação, não única, ao ECA (CUNHA; SALES; CANARIM, 2007, p. 42).

Considerando os desafios apresentados por essa instituição-organização, em 2014, foi formada uma equipe de pesquisa interinstitucional que tinha por objetivo explorar as experiências de gênero e sexualidade de jovens em privação de liberdade. Esta equipe foi dividida em subequipes que focaram em três unidades de internação: uma feminina e duas masculinas. $\mathrm{O}$ presente trabalho apresenta parte do percurso realizado em uma das unidades masculinas, situada em um bairro periférico do Rio de Janeiro, onde foi realizada uma pesquisa-intervenção de 2015 a 2017. O foco será dado a reflexões sobre a forma em que gênero e sexualidade são contempladas (ou não) no trabalho com os jovens homens, por uma instituição que se pretende (socio)educativa.

\section{ABORDAGEM TEÓRICA, METODOLÓGICA E POLÍTICA}

A pesquisa-intervenção foi realizada a partir da perspectiva cartográfica, ao ser constituída pelo devir, pelo movimento, pela atenção, pela busca de irregularidades e pelas surpresas que produzem mundo (LEITE, 2014; BENET; MERHY; PLA, 2016), procura acompanhar processos e provocar, deslocar, movimentar e tensionar as forças coletivas que compõem o campo, bem como abrir passagem para afetos (ROLNIK,1989) e criar possibilidades de construção de um comum (BICALHO; ROSSOTTI; REISHOFFER, 2016). Dessa forma, a cartografia, como pesquisaintervenção, tem um caráter político (NASCIMENTO; COIMBRA, 2008).

A partir desse princípio, é possível assumir o compromisso político feminista de emancipação das mulheres e de justiça social, o que, em uma pesquisa, se traduziria na produção de conhecimento que descreva e analise desigualdades de gênero, ao tempo em que propõe rupturas da lógica de manutenção do poder, da dominação e da discriminação (CASTAÑEDA, 2014). Assim, sugerem-se pistas para uma cartografia feminista,

compreendidas como instigações éticas, políticas e estéticas para pensar e criar pesquisas-intervenções que, ao tempo em que tensionam os campos de pesquisa e as relações entre grupos e instituiçõesorganizações acadêmicas, militantes e governamentais, são constituídas pelo cuidado e a sensibilidade cotidianos, ao propor processos de produção de conhecimento e/como transformação (DE GARAY HERNÁNDEZ, 2018, p.36). 
Uma dessas pistas se relaciona com os sujeitos que chamamos a participar das nossas pesquisas-intervenções feministas. Algumas pesquisadoras têm destacado a importância de fazer pesquisas feministas com homens, entendendo-os como seres marcados pelo gênero (VIVEROS, 2002), portanto importantes para pensar nas dinâmicas das relações de poder e nos questionamentos a essas dinâmicas (GOMES, 2002). Igualmente, parece fundamental considerar que as subjetividades não são produzidas apenas pelo gênero. Os dispositivos de raça, classe social, geração, localidade e sexualidade também compõem os processos de subjetivação através da sua instauração nas instituições-organizações, tais como a escola, as comunidades religiosas, a mídia e o próprio Sistema Socioeducativo.

Desta forma, podemos pensar que "estudos sobre homens que se movimentam em lugares marginalizados sejam relevantes na fabricação das performatividades diversas, assim como na produção de ações no campo em que eles circulam" (DE GARAY HERNÁNDEZ, 2018, p. 77). Isso não significa que os estudos sobre homens devam ser apenas acerca de homens marginalizados por sua raça, idade ou classe social. É importante chamar esses homens para, por meio de pesquisas-intervenção, serem capazes, junto conosco, de pensar no sistema machista, racista e cisheteronormativo, possibilitando linhas de fuga.

É por isso que acionamos o conceito de performatividades de gênero (BUTLER, 2003), e, mais especificamente, performatividades masculinas, entendidas como agenciamentos de repertórios que produzem narrativas, práticas, experiências corporais, fronteiras, processos sensíveis, jogos nos territórios políticos. Nas tensões, contradições e disputas dos modelos de masculinidade, as performatividades extraem a potência e a diversificação, transbordando o sistema binário.

Outro conceito preponderante na análise é o de instituição que, a partir da Análise Institucional, pode ser pensada de várias formas: como "estabelecimentos ou organizações, com existência material e/ou jurídica” (RODRIGUES; SOUZA, 1991, p. 31), por exemplo, as unidades socioeducativas; como "dispositivos instalados no interior dos estabelecimentos" (p.31), ou seja, como práticas ou técnicas, tais como a organização dos espaços nas unidades; e, finalmente, num sentido mais conceitual, "não localizável", como uma "forma que produz e reproduz as relações sociais" (p.33), ou seja, como formas gerais ou hegemônicas que se instrumentam em estabelecimentos e organizam práticas, com um "sentido ativo de manter de pé a máquina social ou até de produzi-la” (p. 33), tais como o machismo, o racismo e a cisheteronormatividade. 
É assim que mergulhamos em uma instituição-estabelecimento ocupada por jovens de 12 a $21 \operatorname{anos}^{4}$, a maioria provindos de favelas e/ou periferias, a maioria de contextos comunitários empobrecidos, a maioria descendentes da diáspora africana. Muitos deles, mas não todos, estão envolvidos com as facções do tráfico de drogas ilícitas de diversas formas, desempenhando funções desde os mais baixos escalões, até os cargos mais altos, o que faz dessas facções instituições-organizações preponderantes nos processos de subjetivação dos jovens e na forma de organização das unidades socioeducativas. Unidades também ocupadas por profissionais que, da mesma forma, são seres generificados, racializados, sexualizados e participam de relações de poder.

A pesquisa-intervenção teve várias etapas que foram se compondo na medida em que eram gerados espaços comuns e possíveis com o campo. Primeiramente, realizamos duas rodadas de atividades em grupos de 05 a 12 jovens. Na primeira rodada, utilizamos fotografias como disparadores de conversas e, na segunda, pedimos para os jovens desenharem uma silhueta do tamanho de uma pessoa e inventarem um personagem e uma história para essa silhueta. Simultaneamente, realizamos entrevistas individuais e em grupos com profissionais da unidade. Foi assim que fomos elaborando alguns analisadores (RODRIGUES, 2005) que enunciavam as tramas dos dispositivos de gênero e sexualidade nas vivências tanto na pista quanto dentro da unidade: a visita íntima, a regulação da masturbação por parte dos jovens, a visita familiar, a entrada de cartas e fotografias, a divisão de espaços dentro da unidade e a negação da existência de relações sexuais entre os jovens. Alguns desses analisadores serão trabalhados neste texto.

Posteriormente, oferecemos um curso de extensão a profissionais dos diversos segmentos - equipe técnica, agentes socioeducativos/as, docentes da escola que se encontra dentro da unidade e pessoal administrativo -, buscando, por meio dos analisadores, convocar a enxergar o gênero e a sexualidade como partes importantes da socioeducação. Esse curso culminou com a proposta de ações coletivas por parte das/os próprias/os profissionais, com os jovens. Participamos de algumas delas.

Meses depois, voltamos à unidade para realizar entrevistas individuais com os jovens, debruçando-nos sobre suas trajetórias singulares. Finalmente, fomos convidadas a realizar mais um curso de extensão, dessa vez, voltado à implementação do preservativo na unidade, a partir de uma perspectiva de Direitos Sexuais e

\footnotetext{
${ }^{4}$ No caso dos que foram internados antes de fazer 18 anos, tendo que cumprir uma medida de mais de um ano.
} 
Reprodutivos. No total, trabalhamos com 163 jovens e 50 profissionais, sendo que algumas pessoas participaram em mais de uma etapa.

\section{PENSANDO A SOCIOEDUCAÇÃO}

Frente à violência urbana se intensificando devido aos impactos do capitalismo, vemos cada vez mais a consolidação de discursos de criminalização da pobreza e da população negra jovem, o que produz um quadro de genocídio material e simbólico (FERREIRA e CAPPI, 2016). Nesse quadro, o Estado se apresenta nos contextos comunitários empobrecidos seja em forma repressiva e seletiva, no controle militarizado, ou domesticadora através de dispositivos tutelares, e no cerceamento de direitos de moradia, saneamento básico, educação, saúde, cultura, esporte, comunicação e lazer, incluindo apoio a propostas locais e culturas alternativas dos jovens. Assim, observamos múltiplos exemplos de omissão e criminalização de projetos de rádios comunitárias, jornais, grupos de educação e saúde popular, artistas e bailes funk, moradias autogestionárias, religiões de matriz africana, dentre muitos outros, bem como seu controle e/ou perseguição por parte dos grupos armados que atuam nos territórios. Desta forma, os repertórios existenciais dos jovens acabam se constituindo em contextos bélicos, enquanto

\footnotetext{
as instâncias de poder estatal, com suas redes de violência, disciplina, controle e tutela, mata ou captura alguns desses jovens através da sua homogeneização, assim como outros que, atravessados pela injustiça social e racial, acabam por erro sendo atingidos pelos corpos de segurança ou por instituiçõesestabelecimento de privação ou restrição de liberdade (DE GARAY HERNÁNDEZ, 2018, p.128).
}

Nesse contexto, os discursos não só atravessam os poros dos muros das unidades socioeducativas, mas constituem suas práticas e proposições. Nesse sentido, ao longo da pesquisa-intervenção, foi importante explorar as noções de socioeducação e educação. No discurso de gestores/as, a instituição-organização está passando por uma mudança de paradigma, passando de um foco na punição para algo que frisa a responsabilização. No entanto, escutamos recorrentemente narrativas de alguns/as profissionais pautadas em uma lógica que articula machismo, racismo e elitismo, responsabilizando as famílias dos jovens, especialmente as mães, pela forma como os jovens cumprindo medida socioeducativa exercem suas vidas. Esses discursos muitas vezes consideram a liberdade excessiva da mulher como provocadora de um 
enfraquecimento da estrutura e da educação familiar, enunciada como uma ausência do entendimento do respeito a superiores, menosprezando um olhar crítico sobre a desigualdade social como produtora de repertórios violentos aos quais os jovens aderem. Para essas pessoas, a falta de tapa provocou a aproximação dos jovens à vida do crime, pois não aprenderam os limites e o respeito a uma autoridade incontestável. No entanto, outras/os profissionais apontaram que alguns jovens justamente se aproximaram das facções para tentar compensar uma vida de violência familiar, por exemplo, vingando pais ou padrastos violentos, o que também escutamos nos relatos dos jovens.

Assim, perspectivas que não contemplam os processos sociopolíticos de injustiça social acabam criminalizando os jovens e suas famílias, não apenas no sentido concreto da penalização, mas como um projeto disciplinador onde o Degase entra como a instituição que vai resolver essas falhas familiares, corrigindo o sujeito (SCISLESKI, et. al., 2014) que provém dessa criação deformada que faz com que os jovens cheguem tortos e a gente tenta alinhar. Alinhar com práticas violentas físicas, psicológicas e morais, como escutamos em vários relatos dos jovens e presenciamos em alguns momentos no cotidiano da unidade. Assim, a educação é efetivada através da punição em uma lógica atrelada às noções sobre as trajetórias desses jovens e o que as pessoas acreditam que eles devem vivenciar nesse espaço (DE GARAY HERNÁNDEZ, 2018, p. 115). Nesse sentido,

a aposta nas medidas socioeducativas como um mecanismo de proteção e promoção é um grande desafio para a gestão da política de direitos ao adolescente e para uma pedagogia emancipatória. Como será possível levar a cabo o projeto de uma "pedagogia da presença" em um cenário de serviços burocráticos em que o ideal da punição se sobressai? (MALVASI, 2011, p. 160)

Ou, como apontado por Andrea Scisleski,

como podemos pensar a medida socioeducativa de internação como uma instância educacional quando se utiliza da privação de liberdade e da disciplina como instrumento de educação? Como a disciplina em questão vem sendo operacionalizada em nome da educação? (SCISLESKI, et. al., 2014, p. 662)

Por outro lado, várias/os profissionais afirmaram que as condições da instituição - estabelecimento no sentido de garantia dos direitos à educação, saúde e cidadania, tem mudado e melhorado, possibilitando diálogos e ações que antes eram impossíveis. 
Um diretor apontou que o Degase é um ponto estratégico de políticas públicas, porque acaba garantindo um lugar social para esses jovens, mesmo isso não sendo a situação ideal. Por sua vez, uma profissional frisou não só a garantia, mas a educação sobre esses direitos, o que, na experiência dela, também acontece apenas no momento em que o jovem chega ao Degase.

Assim, o engajamento em atividades artísticas, culturais, educativas, de saúde e meio ambiente, bem como em projetos profissionalizantes, foram ressaltados por alguns jovens. Alguns deles, inclusive, expressaram que é só quando estão cumprindo medida socioeducativa de internação que assistem à escola.

Apesar dos vários aspectos positivos, vale a pena problematizar que muitas destas ações de profissionalização e educação parecem estar direcionadas apenas à prevenção da delinquência juvenil, como uma forma de "afastar" os jovens do tráfico, o que também é perceptível em vários projetos em favelas e/ou periferias. Parece que, contrário ao que acontece em outros contextos, a proposta não é necessariamente a garantia de direitos de crianças e jovens e a busca das suas potencialidades, mas evitar que estes/as se envolvam ou continuem envolvidos/as em práticas violentas, sem enfrentar a desigualdade social que constitui essas violências, marcada pelo capitalismo que ao tempo em que os faz pensar que o tráfico seria a única forma de acessar ao que a sociedade valoriza - o que os jovens chamam de ostentação -, os explora e os mata massivamente enquanto enriquece a um pequeno número de pessoas distantes desses contextos. Nesse sentido, vale a pena nos interrogarmos sobre o viés colonialista desses projetos, a partir do qual não conseguem contemplar os desejos, interesses e culturas dos jovens, fazendo da sua proposta uma perspectiva distante deles e expulsando-os simbolicamente (RODRIGUES, 2015).

Um jovem que participou da pesquisa-intervenção disse:

É bom ficar um pouco longe da rua, parar pra pensar um cado. Às vezes caos da família é ruim, vocêficar um pouco longe é bom pra você pensar um cado também. Você sair, ou você morre, ou você volta pra casa de novo. É bom você pensar assim

Gostar da cadeia ninguém gosta, né? Mas gosto que aqui nós fica guardado, se não, lá fora não poderia pensar muito também.

Com essa fala, vemos como a privação de liberdade, com os projetos que ela possa contemplar, pode afastar os jovens provisoriamente do contexto onde estão sendo violentadosm onde estão participando de violências, mas ao mesmo tempo, reproduz a 
ideia de que o trabalho de "pensar" é individualizado e focado nos jovens, não nos processos sociopolíticos. Dessa forma, sair de trajetórias constituídas como criminais implicaria passar a fazer parte da força de trabalho legitimada e não necessariamente os afastaria de violências que seus corpos e territórios sofrem cotidianamente.

Todavia, a fala do jovem sugere que para ele, o tempo no Degase diz apenas respeito a um tempo guardado, distante do caos da rua, sem fazer referência ao que a socioeducação poderia fazer de forma afirmativa. Isso pode apontar também para o fato de que o paradoxo da "demanda por ações socioeducativas pautadas pelo cunho pedagógico e não repressor", que "contrai a contenção e a educação", "é intensificado pela precariedade das unidades, [...] acentuada pela superlotação" (VINUTO; ABREO; GONÇALVES, 2017, p. 56).

Neste campo de forças que circunscrevem as práticas socioeducativas, é possível observar o reforço dos especialismos nas áreas de atuação dos/as profissionais, que exercem diversas funções no processo de cumprimento da medida dos jovens e produzem saberes e exercem poderes sobre eles, contribuindo com o entrelaçamento de códigos institucionais que estabelecem hierarquias através da judicialização e burocratização da vida.

Os agentes socioeducativos, por exemplo, são permanentemente colocados/as e limitados no lugar de manutenção da segurança e de gestão de riscos, tendo dificuldades em desconstruir e participar de outra forma, se afirmando como nós do cadeado e se posicionando (e sendo posicionados) constantemente em uma disputa de performatividades masculinas com os jovens, que os chamam de vermes - não publicamente - e seguem a regra faccional de não estabelecer contato com eles, ao menos que seja estritamente necessário.

Por sua parte, as equipes técnicas, formadas por psicólogas/os, pedagogas/os e assistentes sociais, enfrentam um cotidiano profissional extremamente burocratizado e cujas principais funções são produzir uma quantidade imensa de relatórios, produzindo o indivíduo ao avaliá-lo, como uma prática política disciplinar, adequando-o à sociedade (SCISLESKI, 2014); e filtrar cartas e fotografias que as famílias levam para os jovens, delimitando um lugar de vigilância. Já as/os docentes enfrentam o desafio da grande diversidade de escolaridades entre os jovens, bem como da rotatividade destes na unidade, o que dificulta uma organização e fluxo de conteúdo.

No entanto, algumas linhas de fuga foram acompanhadas e potencializadas pela pesquisa-intervenção, com profissionais dos diversos segmentos que apesar das Momento: diálogos em educação, E-ISSN 2316-3100, v. 28, n. 3, p. 285-302, set./dez, 2018. 
dificuldades buscam constantemente realizar atividades com desdobramentos interessantes para os jovens, no sentido de criar um diálogo diferenciado com eles e de buscar uma socioeducação sensível e propositiva. Desta forma, a pesquisa-intervenção se reafirma como um

modo de investigação que ganha corpo entre a macro e a micropolítica, considerando como desafio a analítica das implicações coletivas com a produção do sentido, processo que transversaliza metodologia e problema de pesquisa, produção de conhecimento e produção de modos de existência (p.536). [...]. A pesquisa-intervenção tem como objetivo a desnaturalização de um cotidiano vivido nas suas constâncias como atemporal, colocando atenção no que acontece, nas situações que resistem aos modelos, no que, nas sucessivas repetições, tensiona as crenças, os valores, a lógica que norteia a rotina. Nessa perspectiva, cotidiano não é uma dimensão fechada 'em si mesma', pois ele se constitui também na dimensão das mudanças em que podemos ser afetados, intensificando um presente que produz rupturas, fazendo diferença nos modos de entender e sentir a realidade - uma diferença marcada por exercícios de singularização (p.537). [...] O campo de intervenção nos remete ao espaço de interlocução, ao território de encontros possíveis entre pesquisador e comunidade envolvida no processo de investigação (p.540) (ROCHA; UZIEL, 2008, p.536-540).

Alinhada com essa proposta, a cartografia feminista aqui apresentada possibilitou pensar nos mecanismos em que certas normativas de gênero e sexualidade são instauradas no cotidiano da unidade socioeducativa, e como elas podem ser postas em análise através das ações propostas na pesquisa-intervenção, buscando desnaturalizar algumas noções e práticas institucionais relacionadas a essas normativas através de processos de interlocução com os jovens e com profissionais.

\section{PROVOCANDO A SOCIOEDUCAÇÃO}

Para pensar o até aqui discutido, apresento dois momentos/processos da pesquisa-intervenção em que conseguimos movimentar provocações no nível micropolítico da unidade. O primeiro aconteceu pouco tempo depois do primeiro curso oferecido a profissionais. Uma das docentes da escola que participou do curso convidou a nossa equipe para realizar uma atividade na Semana do Bebê, evento do Degase voltado a jovens pais e mães com o objetivo delas/es refletirem a respeito do exercício da parentalidade. Propusemos a elaboração de árvores genealógicas, ou melhor, de rizomas genealógicos, que trouxessem à tona a multiplicidade das configurações familiares dos jovens. Cada um dos 35 jovens pais realizou seu rizoma com os materiais 
fornecidos, e depois discutimos o que eles tinham colocado e como isso falava sobre suas experiências. A atividade foi extremamente interessante para discutir várias questões com os jovens. Na medida em que apresentavam seu rizomas, íamos puxando fios, provocando conversas, introspecções, cumplicidades.

Uma das questões se relaciona com o já apresentado no que diz respeito aos processos de culpabilização das famílias, lógica reproduzida em falas que afirmam que os jovens estão no Degase porque têm famílias desestruturadas, ou que a criminalidade é transmitida de geração em geração nas famílias, onde os jovens não têm referências positivas. Ao falar de referências de vida, os jovens - e a própria professora - se surpreenderam com a heterogeneidade das suas vidas: enquanto um jovem falava meu pai morreu e a minha mãe ficou presa 10 anos, se eu seguisse a minha mãe, estaria pior do que estou, outro falava que se tivesse seguido o exemplo do pai, nem estaria aqui, pois seus pais eram trabalhadores. Parece importante aqui "vislumbrar que as trajetórias dos jovens e suas famílias, mesmo perpassadas por instituições-forma e instituições-organização, são múltiplas e singulares, o que não significa que as problemáticas sejam individuais e nem tampouco que a família seja a única instituiçãoorganização que constitui as nossas existências" (DE GARAY HERNÁNDEZ, 2018, p. 119).

Assim, ao pensar na noção de "família desestruturada"

devemos atentar para a existência de especificidades decorrentes da hegemonia cultural, lembrando que o construto-padrão mais aceito pela sociedade é o da classe média. Infelizmente não há referências às famílias de classes populares que não sejam estigmatizadoras, sendo essas comumente denominadas desestruturadas ou desajustadas" (ASSIS, 1999, p. 41).

Devemos, igualmente, analisar quais os motivos dessa suposta desestruturação, como apontado por Mônica Cunha, militante do Movimento Moleque, composto por mães e familiares de jovens cumprindo medida socioeducativa, quem disse em uma entrevista: as nossas famílias não são naturalmente desestruturadas, o Estado que as desestrutura quando mata e encarcera os nossos companheiros e os nossos filhos, e nos adoece até a morte. Assim, as mortes e o encarceramento dos homens negros e empobrecidos acabam responsabilizando as mulheres negras empobrecidas pelo sustento das famílias, reproduzindo o machismo - posteriormente adjudicado apenas a esses homens -, o racismo e a desigualdade de classe.

Relacionado com isso, os jovens também revelaram uma grande diversidade de Momento: diálogos em educação, E-ISSN 2316-3100, v. 28, n. 3, p. 285-302, set./dez, 2018. 
experiências com pais, padrastos, avôs e companheiros de avós que deles cuidaram como se fossem seus, fissurando narrativas superficiais da "ausência paterna", e inclusive das práticas da paternidade. A partir disso, pensaram nas suas próprias paternidades, muitas vezes reproduzindo discursos em que a responsabilidade tanto da prevenção da gravidez quanto da criação das crianças é das mulheres, enquanto a eles fica destinada a função tanto de garantir uma gravidez - como sinal de virilidade -, quanto do sustento financeiro - reforçando, muitas vezes, a necessidade de se envolver nas facções do tráfico. No entanto, alguns também mergulharam em outras perspectivas, expressando sentimentos e desejos em outros registros que permitem pensar experimentações coletivas que explorem outras performatividades masculinas que, por sua vez, tenham efeitos na emancipação das mulheres.

Dessa forma, através de uma atividade participativa e em parceria com a professora, que engajou a maioria dos jovens no percorrido das suas próprias histórias e afetos e na visibilização da sua heterogeneidade, conseguimos desenhar algumas linhas de fuga para escapar de discursos homogeneizadores e naturalizados.

Um outro momento/processo de provocações feministas foi o segundo curso que oferecemos aos/às profissionais, que inclusive foi resultado de um convite realizado por algumas parceiras da unidade. Através do objetivo bem concreto de implementação da camisinha na unidade, que acionava analisadores desenvolvidos ao longo da pesquisa, como a falta do direito à visita íntima ou a negação das relações sexuais entre os jovens, o curso visava uma discussão coletiva na perspectiva dos Direitos Sexuais e Reprodutivos dos jovens. O programa foi realizado visando contribuir com a "sistematização do entendimento do gênero e da sexualidade como organizadores da vida na unidade e como fundamentais ao pensar a socioeducação, vista como um exercício pedagógico de produção de uma plataforma de ações e de ressignificação dos diversos lugares sociais" (DE GARAY HERNÁNDEZ, 2018, p. 354).

Para isso, foram realizados importantes movimentos de convocação de todos os segmentos de profissionais, incluindo tanto as parcerias que estabelecemos como equipe de pesquisa, permanentemente dedicadas a pensar formas de garantir os direitos na instituição-estabelecimento, quanto as pessoas que se mostraram mais resistentes às nossas propostas. Igualmente, conseguimos realizar uma articulação com a Secretaria de Saúde, que participou de um dos módulos do curso. Destaco também a participação de um grupo de jovens da unidade em alguns dos encontros de planejamento estratégico da implementação do preservativo. Eles estavam, naquele momento, participando do 
curso de Promotores de Saúde, facilitado por uma assistente social da unidade e de grande relevância no que tange ao projeto de socioeducação até aqui discutido.

O uso da camisinha está contemplado na publicação "Socioeducação: Legislações, Normativas e Diretrizes Nacionais e Internacionais", do Novo Degase (2013) como parte das "ações e práticas educativas" (p. 329). No entanto, como foi amplamente debatido no curso, ele não é considerado de forma generalizada como um tema importante para a socioeducação. Muito pelo contrário, as pessoas resistentes à sua implementação insistiram que ela seria impossibilitada pelas regras de convívio $^{5}$ dos jovens, instauradas pelas facções e transmitidas e vigiadas por eles. Conforme foi argumentado, o simples fato de disponibilizar o preservativo faria com que a instituição assumisse oficialmente que as relações sexuais entre os jovens existem, o que configuraria uma afronta ao modelo cisheteronormativo de masculinidade que eles sustentam, o ser sujeito homem, e que por sua vez é naturalizado pelas práticas profissionais. Essas regras de convívio foram enunciadas recorrentemente, inclusive em momentos em que os jovens pareciam estar dispostos a traçar estratégias de ação, o que fazia com que eles mesmos recuassem e afirmassem a impossibilidade de implementar o preservativo sem provocar conflitos violentos - e até letais - na unidade ou inclusive implicações para eles com seus patrões fora dela. Foi impressionante ver de que forma essa proposta provocou e enunciou as tensões institucionais, nitidamente relacionadas com gênero e sexualidade.

No entanto, apesar de as resistências parecerem ter mais eco do que as propostas, pois no final do curso não foi possível implementar a camisinha, provocando angústias na nossa equipe, algumas parcerias tanto entre as equipes quanto entre os próprios jovens expressaram a relevância das provocações realizadas, especialmente por elas terem sido abertas ao diálogo, situadas, sensíveis e comprometidas com os direitos e preocupações não só dos jovens, como também das/os próprios/as profissionais. Por sua vez, alguns/as deles/as apontaram que um trabalho semelhante não teria sido possível em outro momento da unidade e do Degase, o que já apontava avanços, bem como novos desafios para a instituição-organização.

\footnotetext{
${ }^{5}$ Toda vez que um jovem chega a um alojamento, ele é orientado com as regras de convívio, muitas das quais estão relacionadas com a contenção da sexualidade: não é permitido quebrar (se masturbar) nos dias da visita familiar nem no dia seguinte, por respeito às familiares mulheres; não é permitido olhar as fotos e cartas dos outros, os homens que se relacionam sexualmente com outros devem ser retirados do alojamento e alocados no alojamento chamado de seguro, dentre outras.
}

Momento: diálogos em educação, E-ISSN 2316-3100, v. 28, n. 3, p. 285-302, set./dez, 2018. 


\section{CONSIDERAÇÕES FINAIS}

Poucos meses depois desse segundo curso, tivemos um encontro com as/os profissionais que participaram dele. Ao perguntarmos sobre o grupo de jovens promotores de saúde, uma técnica nos informou que o jovem que mais firmemente mostrou adesão ao discurso da impossibilidade de implementação da camisinha pela afronta que ela representava às regras de convívio, das quais ele se considerava guardião e responsável frente ao patrão, tinha sido morto duas semanas depois de sair em liberdade, no momento em que estava chegando à barbearia.

Esta notícia nos chocou muito. Apesar de não saber exatamente quais as circunstâncias do seu assassinato, o acontecimento nos provocou a pensar de que forma as regras que ele tanto defendia, pautadas na lógica bélica perpassada pelo machismo, o racismo e o capitalismo, não conseguiram protegê-lo da morte. Assim, um jovem comunicativo, com uma visível capacidade de liderança e articulação política, não teve a oportunidade de questionar as próprias regras que o mataram, pois no momento em que essa abertura foi sugerida, forças dentro da própria instituição-organização reforçaram seu caráter de imutável. Se, como um gestor do Degase apontou, socioeducação implica educar para a sociedade, o não questionamento dessas regras, sua naturalização e seu patrulhamento, acabam se constituindo como travas para esse processo e para a afirmação de vida, provocando mortes e violências cotidianas dentro e fora do estabelecimento.

No entanto, apesar dessas profundas dores e perdas, a partir da cartografia feminista conseguimos perseguir fissuras nesses códigos e regras, mostrando de que forma em áridos panoramas, o amor e a vida pedem/fazem/forçam passagem, em um “devir revolucionário" (DELEUZE, 2008). Acompanhamos, por exemplo, a formação de um casal afetivo-sexual de jovens que, na contracorrente dos pressupostos e possibilidades de percursos dentro do estabelecimento, assumiram seu amor e seu desejo um pelo outro, conseguindo um reconhecimento institucional e, inclusive, a oferta de preservativos no seu alojamento.

A partir da produção de campos moleculares de afetação e de trabalho na singularização como possibilidade concreta de luta contra instituições-forma como o machismo e o racismo, conseguimos em vários momentos movimentar e conectar algumas questões com os jovens a partir das suas experiências, como exprime a simples frase enunciada por um deles em um momento de provocação: agora vocês me pegaram! 
Mergulhamos, com eles, através de pistas de experimentação cartográfica feminista, nas fronteiras, nos poderes, nas multiplicidades. Nos debruçamos na produção microscópica de marginalidades, diferenças, comuns, bem como nas suas dobras nos afetos, nos erotismos, nas temporalidades (ritmos) e nas violências nas paisagens da cidade e do estabelecimento, onde convivem diversos paradigmas de punição, educação e gestão de sujeitos, corpos e sexualidades, bem como diferentes projetos de gênero que ora se aproximam, ora se distanciam (DE GARAY HERNÁNDEZ, 2018, p. 385).

Desta forma, parece primordial considerar gênero e sexualidade como eixos fundamentais de ação tanto em instituições-estabelecimentos de privação de liberdade, quanto na fundamentação de propostas educativas. E é justamente desses espaços que os avanços conservadores conseguem expulsar as discussões sobre gênero e sexualidade, conscientes do potencial transformador e emancipatório. Como apontado pela educadora popular argentina Claudia Korol,

Gostaria que pudéssemos avançar na cumplicidade, no acompanhamento entre nossas distintas experiências, para pôr mãos à obra em novos projetos coletivos, onde descobríssemos a enorme capacidade de criação de teoria e prática que há em nossas experiências, e encontrássemos as maneiras de multiplicá-las até conseguir transtrocar o senso comum conservador e se tornasse insuportável conviver cotidianamente com tantas injustiças. Para podermos gritar a partir de cada ferida, fazer memória a partir de cada cicatriz. Para habitarmos a política e a paixão como territórios recuperados e despejarmos o horizonte de esterilizantes debates de seita. Para que nossos corpos sejam os territórios complexos dos quais partimos para o amor e para a rebeldia e nos que a revolução não fique inscrita como um sonho eterno, mas como uma vivência permanente e cotidiana (KOROL, 2010, p.191, tradução livre)

Assim, em nossa pesquisa-intervenção, propusemos por em análise as instituições-forma que nos atravessam e compõem, frisando a importância da educação em gênero e sexualidade com esses jovens, especialmente a partir de uma perspectiva e uma ética feministas, que desestabilizem os pressupostos machistas, racistas, cisheteronormativos e capitalistas de formação humana. E que nos liberte a todas e todos.

\section{REFERÊNCIAS}

ABDALLA, Janaína. Poder, Estado e adolescentes envolvidos em atos ilícitos. In: ABDALLA, Janaína; PEREIRA, Maria; GONÇALVES, Tania. Ações socioeducativas: estudos e pesquisas. Rio de Janeiro: Degase. 2016a. p. 23-41 
ABDALLA, Janaína. Socioeducação e educação social. In: ABDALLA, Janaina; VELOSO, Bianca; VARGENS, Paula (Orgs.) Dicionário do Sistema Socioeducativo do Estado do Rio de Janeiro. Rio de Janeiro: Novo DEGASE. 2016b. p. 348-351

BENET, Marta; MERHY, Emerson; PLA, Margarida. Devenir cartógrafa. Athenea Digital. v. 16, n.3, p.229-243, 2016.

BICALHO, Pedro; ROSSOTTI, Bruno; REISHOFFER, Jefferson. A pesquisa em instituições de preservação da ordem. Rev. Polis e Psique. v.6, n.1, p.85-97. 2016.

BRASIL. Estatuto da Criança e do Adolescente, Câmera dos Deputados, Lei no 8.069, de 13 de julho de 1990. DOU de 16/07/1990 - ECA. Brasília, DF.

BUTLER, Judith. Problemas de gênero: feminismo e subversão da identidade. Tradução de Renato Aguiar. Rio de Janeiro: Civilização Brasileira, 2003, 236f.

CASTAÑEDA, Patricia. Investigación feminista: caracterización y prospectiva. In: MONTIEL, Edgar (ed.). Pensar un mundo durable para todos edgar. Lima: UNESCO, 2014, p. 151-164

COIMBRA, Cecília; NASCIMENTO, Maria. Implicar. In: FONSECA Tania; NASCIMENTO Maria; MARASCHIN, Cleci (Orgs.) Pesquisar na diferença: um abecedário. Porto Alegre: Sulina, 2012, p. 129-131

CUNHA, Mônica; SALES, Rute; CANARIM, Claudia. O Movimento MOLEQUE, Movimento de Mães pelos Direitos dos Adolescentes no Sistema Socioeducativo. In: Comissão de Direitos Humanos do CRP-RJ [org.] Direitos humanos? o que temos a ver com isso? Rio de Janeiro: Conselho Regional de Psicologia, 2007, p. 25-48.

DE GARAY HERNÁNDEZ, Jimena. O Adolescente dobrado: cartografia feminista de uma unidade masculina do Sistema Socioeducativo do Rio de Janeiro. Tese (doutorado) Psicologia Social, Universidade do Estado do Rio de Janeiro. 2018

DELEUZE, Giles. Conversações. Tradução de Peter Pal Pelbart. São Paulo: Editora 34. 2008, 234f

DEPARTAMENTO GERAL DE AÇÕES SOCIOEDUCATIVAS. Socioeducação: Legislações, Normativas e Diretrizes Nacionais e Internacionais Volume 2. Novo Degase: Rio de Janeiro. 2013

FERREIRA, Poliana; CAPPI, Riccardo. Contando as mortes de jovens negros: narrativas de um real insustentável. Cadernos do CEAS, Salvador, n. 238, p. 543-467, 2016.

GOMES, Rosely. Mediando oposições: sobre as críticas aos estudos de masculinidades. In: ALMEIDA, Heloisa. et. al. (eds.). Gênero em matizes. Bragança Paulista: Editora da Universidade São Francisco, 2002, p. 213-241.

KOROL, Claudia. Hacia una pedagogía feminista. Pasión y política en la vida cotidiana. In: ESPINOSA, Yuderkys (coord.). Aproximaciones críticas a las prácticas 
teóricopolíticas del feminismo latinoamericano. Buenos Aires: En la Frontera, 2010. p.183-192

LEITE, Maynar. Cartografar (n)a prisão. Estudos e Pesquisas em Psicologia, v. 14, n. 3, p. 795-813. 2014.

MALVASI, Paulo. Entre a Frieza, o Cálculo e a "Vida Loka": violência e sofrimento no trajeto de um adolescente em cumprimento de medida socioeducativa. Saúde Soc., v.20, n.1, p.156-170, 2011.

ROLNIK, Suely. Cartografia sentimental: transformações contemporâneas do desejo. São Paulo: Estação Liberdade, 1989. $248 f$

RODRIGUES, Heliana. "Sejamos realistas, tentemos o impossível!": desencaminhando a Psicologia através da Análise Institucional. In: JACÓ-VILELA, Ana; FERREIRA, Arthur; PORTUGAL, Francisco (Org.). História da Psicologia: rumos e percursos, v. 1. Rio de Janeiro: Nau, 2005, p. 525-594.

ROCHA, Marisa; UZIEL, Anna. Pesquisa-intervenção e novas análises no encontro da Psicologia com as instituições de formação. In: CASTRO, Lucia; BESSET, Vera (org). Pesquisa-intervenção na infância e juventude. Rio de Janeiro: Trarepa, 2008. p.532-556

RODRIGUES, Alexandre. Direitos humanos, segurança pública e cultura de paz: o que a escola tem a ver com isso? In: MEIRELLES, Mauro, et. al., Cidadania e direitos humanos. Porto Alegre: Cirkula. 2015. p.97-110

RODRIGUES, Heliana; SOUZA, Vera. A análise institucional e a profissionalização do psicólogo. In: SAIDÓN, Osvaldo; KAMKHAGI, Vida. Análise institucional no Brasil. 2. ed. Rio de Janeiro: Rosa dos Tempos, 1991. p. 27-45.

SCISLESKI, Andrea, et. al. Medida Socioeducativa de Internação: dos Corpos Dóceis às Vidas Nuas. Psicologia: ciência e profissão, v.34, n.3, p. 660-675, 2014.

VINUTO, Juliana; ABREO, Leandro; GONÇALVES, Hebe. No fio da navalha: efeitos da masculinidade e virilidade no trabalho de agentes socioeducativos. Revista PLURAL, v.24, n.1, p.54-77, 2017.

VIVEROS, Mara. De quebradores y cumplidores: Sobre hombres, masculinidades y relaciones de género en Colombia. Bogotá: Universidad Nacional de Colombia. 2002. $118 f$. 